ఠ

Open Access Full Text Article

METHODOLOGY

\title{
Methodological considerations of investigating adherence to using offloading devices among people with diabetes
}

This article was published in the following Dove Press journal:

Patient Preference and Adherence

\author{
Gustav Jarl ${ }^{1,2}$ \\ 'University Health Care Research \\ Center, Faculty of Medicine and \\ Health, Örebro University, Örebro, \\ Sweden; ${ }^{2}$ Department of Prosthetics \\ and Orthotics, Faculty of Medicine \\ and Health, Örebro University, \\ Örebro, Sweden
}

\begin{abstract}
Foot ulcers are a diabetic complication associated with significant morbidity, mortality, and amputation risk. Offloading devices prevent and heal foot ulcers, but adherence to using these devices is low. The reasons for nonadherence are unclear, and study results are difficult to compare due to methodological heterogeneity. This paper explores aspects of investigating adherence to using offloading devices among people with diabetes and provides recommendations for future studies, focusing on study designs, definitions of adherence, measurement methods, and conceptual frameworks. Most studies use a cross-sectional observational study design, limiting the potential to establish the temporal sequence between predictors and adherence, rule out confounding factors, and establish causality. Studies defining adherence as the length of time the device is worn have often used self-report to measure adherence, which may be unreliable. Studies using activity monitors to measure adherence have defined adherence as the number of steps taken with the device, which excludes weight-bearing activities where no steps are taken. Conceptual frameworks are not made explicit in the current quantitative research. It is concluded that future studies should use a longitudinal design with observational studies to identify patient groups prone to nonadherence and factors that influence adherence and experimental studies to evaluate interventions to improve adherence, focusing on these patient groups and factors. Furthermore, adherence should be defined in terms of relative adherence to using offloading devices during all weight-bearing activities, and objective measurement of adherence (using accelerometers and temperature monitors) should be used whenever possible. Clearly defined conceptual frameworks should guide the choice of factors to include in the study and the analysis of their interactions. By implementing these recommendations, research could provide a stronger evidence base in the future, supporting interventions to increase adherence and thereby improve outcomes for people with diabetic foot complications.
\end{abstract}

Keywords: research design, treatment adherence and compliance, patient compliance, orthotic devices, shoes, diabetic foot

\section{Introduction}

Diabetic foot ulcers are a common and devastating complication of diabetes. The lifetime incidence of diabetic foot ulcers has been estimated to be between $19 \%$ and $34 \%{ }^{1}$ Numerous studies have shown that diabetic foot ulcers are associated with increased mortality, ${ }^{2}$ lower quality of life,${ }^{3}$ high costs, ${ }^{4}$ and increased risk of lower limb amputation. ${ }^{5}$ Offloading devices are a central intervention to prevent and heal diabetic foot ulcers, especially plantar ulcers, which account for almost $50 \%$ of the foot ulcers seen in specialized clinics. ${ }^{6}$ Obviously, the devices can have no effect if the person does not use them, and it is well known that adherence often is low when
Correspondence: Gustav Jarl

Department of Prosthetics and Orthotics, Örebro University Hospital, S-70I 85

Örebro, Sweden

$\mathrm{Tel}+46196025875$

Fax +4619122010

Email gustav.jarl@regionorebrolan.se
Patient Preference and Adherence 2018:12 1767-1775

(c) (1) (8) () 2018 Jarl. This work is published and licensed by Dove Medical Press Limited. The full terms of this license are available at https:/www.dovepress.com/terms.php

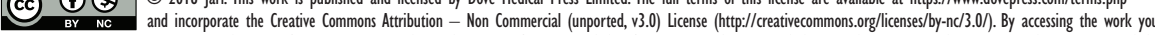
hereby accept the Terms. Non-commercial uses of the work are permitted without any further permission from Dove Medical Press Limited, provided the work is properly attributed. For peminsion for commercial use of this work, please see paragraphs 4.2 and 5 of our Terms (https:/ /www.dovepress.com/terms.php). 
it comes to using devices such as therapeutic footwear, ${ }^{7-15}$ cast walkers, ${ }^{16,17}$ and shoes offloading the forefoot or heel. ${ }^{18}$ Therefore, guidelines recommend the use of nonremovable devices to offload foot ulcers during the treatment period. ${ }^{19,20}$ However, it is not feasible to use nonremovable devices once the ulcer is healed, and $\sim 40 \%$ of ulcers recur within 1 year. ${ }^{1}$ Thus, a better understanding of factors affecting adherence is urgently needed in order to better prevent ulcerations, claimed to be one of the most significant unsolved issues in the care of people affected by diabetic foot complications. ${ }^{21}$

Clinicians often ask patients about adherence when it is believed to be low. Naturally, the focus is on finding reasons for the patient being nonadherent and ways to convince the patient about the benefits of adherence. However, this is a problematic approach for understanding adherence in general. First, clinicians usually ask for reasons that work against adherence but not for reasons working for adherence, resulting in too few factors being identified as influencing adherence. Second, clinicians seldom ask adherent patients about factors affecting their adherence, that is, they overlook a potential control group with which to contrast the nonadherent patients' answers. Thus, complaints such as the appearance of the shoes may seem to be important for nonadherence although adherent patients may be equally concerned about this. ${ }^{22,23}$ Third, patients can only give reasons that they are consciously aware of, such as the appearance and weight of the therapeutic shoes, and may not give reasons that they are less aware of, such as sensory neuropathy eliminating pain when walking on ulcerated feet without the shoes. In summary, the clinical approach to investigating adherence involves the risk of giving a simplistic understanding of adherence, in which too few factors are identified and their role in adherence is misunderstood.

Some studies ${ }^{24,25}$ have used a qualitative approach, which is useful for understanding the subjective experiences, but it suffers from weaknesses similar to the clinical approach. Some quantitative studies ${ }^{26-28}$ have investigated factors affecting adherence, but they have included several diagnoses in the same study. This makes the results more difficult to interpret because patients with different diagnoses, such as rheumatoid arthritis and diabetes, may have different views and priorities regarding footwear. ${ }^{29} \mathrm{~A}$ review from $2016^{30}$ found only six quantitative studies investigating factors affecting adherence to using therapeutic shoes among people with diabetes. The authors found some evidence against using sex, diabetes duration, or ulcer history to predict adherence. The evidence for or against other factors was weak or conflicting. ${ }^{30}$ Only a few studies have been published since then. Crews et $\mathrm{al}^{16}$ found that larger and more severe ulcers, more severe neuropathy, and foot pain predicted better adherence and postural instability predicted worse adherence. Kossioris et $\mathrm{a}^{31}$ found that patients with active foot ulcers were less adherent to wearing appropriate footwear than patients without ulcers. Keukenkamp et a ${ }^{32}$ found that a motivational interviewing intervention improved adherence in the short term, but the improvement was not statistically significant and returned to baseline levels in the longer term. In general, results from studies are difficult to compare because the studies have used different study designs, defined and measured adherence in different ways, and studied different factors that could influence adherence. ${ }^{30}$ Thus, there is a need for a methodological discussion on these topics. The aims of this methodological commentary were to discuss methodological aspects of investigating adherence to using offloading devices among people with diabetes and provide recommendations for future studies. The focus was on choice of study design, definitions of adherence, methods to measure adherence, and conceptual frameworks.

\section{Choice of study design}

Two basic criteria, temporality and statistical association, are fundamental when drawing inferences about causal relationships between exposures and outcome, for example, between certain factors and adherence to using offloading devices.

Temporality means that the exposure precedes the outcome in time. If we want to test whether the belief in the efficacy of the offloading devices affects adherence to using them, we need to establish that this belief precedes adherence and not the other way around. For example, a person who does not wear his or her therapeutic shoes for esthetic reasons may rationalize his or her choice afterward by stating that the shoes were not healing the ulcer. This gives researchers the false impression that lack of belief in the shoes' efficacy is the reason for nonadherence, when the real reason is that he or she finds the shoes unattractive. Therefore, longitudinal studies in which the time sequence of exposure and outcome can be established are preferable to cross-sectional studies. Unfortunately, most studies that assess attitudes to the offloading device and adherence are more or less crosssectional, ${ }^{8,14,22,23}$ making it difficult to separate attitudes as reasons for nonadherence from attitudes as after-the-fact rationalizations. Causality can be especially challenging to investigate when negative patient beliefs and low adherence self-reinforce through a feedback loop, resulting in a "vicious diabetic foot cycle". ${ }^{33}$ In these cases, repeated measurements 
may be needed to follow how beliefs and adherence-related behaviors develop and interact over time.

Statistical association means that there should be a dependency between measures of exposures and measures of outcome. If motivation influences adherence, we expect higher motivation to be associated with higher adherence and lower motivation to be associated with lower adherence. However, spurious correlations can sometimes be found between two variables in an analysis when both variables are correlated with a third variable, a confounder. This may explain some surprising results in the literature. For example, Breuer $^{22}$ found that a higher proportion of adherent patients than nonadherent patients expected to develop ulcers whatever they do, when the opposite would make more sense. It is possible that this association was due to a confounding variable: adherent patients also reported their diabetic foot complications to be more severe, which could have been the true reason for their higher adherence.

Both observational and experimental studies can be longitudinal and thereby establish temporality, but their approaches to investigating statistical associations and ruling out confounding differ. Several observational studies have been published, where researchers measured factors believed to influence adherence and adherence level and investigated statistical associations between the factors and the level of adherence. ${ }^{8,13,14,16,22,23,31,34}$ Univariate analysis has often been used $^{8,13,22,31,34}$ but is not recommended because of the risk of confounding. To counteract this risk, stratified or multivariate analyses can be used, ${ }^{35}$ and the latter has been used in some studies. ${ }^{14,22,30} \mathrm{~A}$ limitation of stratified and multivariate analyses is that all potential confounders need to be identified in advance in order to measure and include them in the analysis. In addition, observational studies are most appropriate for identifying patient groups that demonstrate low adherence and factors that influence adherence. To establish which interventions improve adherence, experimental studies are needed. In these studies, participants are randomized to two or more interventions believed to influence adherence. To the author's knowledge, only one small experimental study has investigated the effects of an intervention (motivational interviewing) on adherence to using offloading devices. ${ }^{32}$ With randomization, both known and unknown confounders tend to be equally distributed in the intervention groups if the study population is sufficiently large, and the risk of confounding the results will be reduced.$^{35}$ However, randomization is no guarantee for equal distribution of potential confounders, and thus, they are often also measured and included in a stratified or multivariate analysis to take their effects into account.
Generally speaking, observational studies should be followed by experimental studies to evaluate interventions to improve adherence, focusing on the patient groups and factors identified in the observational studies. Experimental studies can also be conducted without any preceding observational study. For example, if we know that motivational interviewing improves motivation to use therapeutic shoes, we can conduct an experiment and compare adherence levels between the intervention and control groups, as in the study by Keukenkamp et al..$^{32}$ However, if the effect of motivational interviewing on motivation is uncertain, this approach can be problematic; we do not know whether a lack of effect on adherence indicates that motivational interviewing did not improve motivation, improved motivation did not improve adherence, or a combination of the two. For this reason, it is desirable that the factor believed to mediate the effect (in this case, motivation level) between the intervention (motivational interviewing) and the outcome (adherence) is measured to facilitate interpretation if the results of the experiment are negative.

\section{Defining adherence and nonadherence}

The purpose of offloading devices is to mitigate pressure on the feet when standing or walking, to prevent or heal foot ulcers. Therefore, the abstract definition of adherence in this context would be something akin to "use of the device when putting pressure on the feet". The abstract definition is seldom made explicit in the literature, but two concrete definitions, operationalizations, prevail: device wearing time $e^{7-10,13,15,23,31,34,36,37}$ and number of steps taken with the device. . $^{12,14,17,32,38,39}$ In general, wearing time has been used to operationalize adherence when using self-report, and step count has been used to operationalize adherence when using activity monitors. Operationalizing adherence in terms of wearing time is less clinically relevant, as the goal is not that patients wear the device many days and hours per se but that they use the device when there is pressure on the feet. Operationalizing adherence in terms of step count is thus more clinically relevant but misses the fact that feet are also subject to pressure when the person is standing still. Thus, the operationalization of adherence should take all weightbearing activities into account.

Furthermore, wearing time and number of steps can be operationalized as absolute or relative adherence. Absolute adherence refers to the wearing time or number of steps with the device, while relative adherence refers to the proportion of adherent behavior. Two people may have equal absolute 
adherence, for example, both using the device for 6 hours or 3,000 steps/day, but for one person, this reflects a relative adherence of $100 \%$ and for the other, this reflects a relative adherence of $75 \%$ as a result of also taking 1,000 steps or walking 2 hours/day without using the device. Thus, relative adherence is more clinically relevant to measure than absolute adherence, and to calculate it, we also need to define and measure nonadherence. In studies using activity monitor data to calculate relative adherence, the number of steps taken with the device has been divided by the total number of steps taken (with and without the device). ${ }^{14,16,32}$ In studies using self-report, researchers have either asked participants to estimate the percentage of daytime they wear their devices ${ }^{8,36,37}$ or asked them to estimate the number of days and hours they wear their devices and then calculated the relative adherence on the assumption that total daytime is 16 hours. ${ }^{23,31}$ However, the definition of nonadherence (weight-bearing activity without using the offloading device) deserves more attention; researchers may want to consider whether all nonuse of the offloading device is equally bad and should be lumped together as nonadherence. For example, using no shoes and using conventional shoes can both be classified as nonadherence, but plantar pressures are usually higher when walking barefoot. ${ }^{38-40}$ Thus, there may be a need to define and measure different forms of nonadherence, which has not been done in studies so far. In addition, some studies ${ }^{8,10,14}$ have found that adherence at home is much lower than adherence away from home, pointing toward a need to separate these two forms of adherence in studies and investigate whether different factors affect them.

\section{Methods to measure adherence}

Studies have assessed adherence using structured interviews, ${ }^{10,11,13,31,36,37}$ self-report questionnaires, ${ }^{7,8,15,18,23 \text {, }}$ ${ }^{34,41}$ entries in patients' clinical records, ${ }^{42}$ observations of what shoe type patients wear when attending the clinic, ${ }^{22,31}$ a temperature monitor in the device, ${ }^{9,43}$ a temperature monitor in the device combined with an activity monitor worn around the ankle, ${ }^{12,14,32,44,45}$ or an activity monitor on the device combined with another activity monitor worn around the waist or at the hip. ${ }^{16,17}$ Ideally, the measurement method should be valid, reliable, sensitive to change, and feasible; it should also discriminate different forms of nonadherence. Objective methods such as temperature and activity monitors generally have stronger measurement properties than subjective self-report methods such as interviews and questionnaires. When using self-report, patients may find it difficult to accurately remember their adherence level, and studies on orthotic devices for other medical conditions have shown that self-report overestimates adherence. ${ }^{46,47}$ However, using objective methods, such as temperature and activity monitors, is not without challenges.

When using a temperature monitor in the device to assess adherence, temperature recordings can sometimes be difficult to interpret. Studies in hot and cold climates, such as Italy ${ }^{48}$ and Sweden, ${ }^{43}$ pose specific challenges: high temperatures might be recorded even when the device is not worn and low temperatures might be recorded even when the device is worn, depending on the indoor and outdoor temperatures. One way to overcome this is to validate a cutoff temperature to separate use from nonuse. ${ }^{9}$ Another approach is to use two temperature monitors in the device, one close to the skin and the other further from the skin. ${ }^{44}$ Similar temperature levels would indicate that the device is not being worn, and two different levels would indicate that it is being worn, regardless of whether the recorded temperatures are high or low. Both approaches, using a validated cutoff temperature and using dual temperature monitors, seem valid for use in future studies. However, temperature monitors can only assess whether the device is being worn or not; to assess to what extent the device is worn during weight-bearing physical activities, activity monitors are needed.

A drawback of the traditional activity monitor, the pedometer, is that it only counts steps. Pedometers cannot separate standing (where the feet support the full body weight) from sitting (where the feet support only a fraction of the body weight). Standing time might be important to consider because people with diabetic peripheral neuropathy can spend twice as much time standing as walking. ${ }^{49}$ However, the clinical significance of standing for ulcer prevention and healing is not yet established. On the one hand, plantar pressure when standing often exceeds $3 \mathrm{~N} / \mathrm{cm}^{2}(30 \mathrm{kPa})$, needed to arrest nutritional blood flow in the skin, ${ }^{50}$ especially when barefooted. ${ }^{51-53}$ It may be speculated that because people with sensory neuropathy do not feel discomfort if blood flow is arrested, they would not shift their weight when standing to improve circulation. On the contrary, postural sway, which is believed to counteract the arrest of blood flow caused by plantar pressure, ${ }^{51}$ is increased in people with diabetic sensory neuropathy. ${ }^{54,55}$ One study ${ }^{56}$ found a negative association between standing time and ulcer healing, which lends some support to the significance of measuring standing time, which pedometers cannot do. Activity monitors in the form of accelerometers can be unreliable when it comes to separating standing from sitting, ${ }^{57}$ but some studies have successfully done this using an accelerometer incorporated in a shirt ${ }^{49,56,58}$ 
or attached to the thigh. ${ }^{57,59,60}$ Thus, accelerometers that can separate standing from sitting are preferable to pedometers and should preferably be used when investigating adherence and the significance of standing for ulcer prevention and healing. Two monitors to measure adherence should ideally be used: one accelerometer worn on the body to assess total weight-bearing activities and a second monitor (temperature monitor or accelerometer) attached to the offloading device, to allow assessment of the proportion of weight-bearing activities when wearing the device.

A general problem with temperature and activity monitors is that people who know that their adherence is being monitored may increase their actual adherence or use deceptive strategies to create the impression of high adherence. ${ }^{61}$ Thus, the measures may be biased and not reflect everyday adherence. To overcome this, study designs involving a deceptive element have been suggested. ${ }^{62}$ There are different degrees of deception involved: stealth monitoring, where participants neither know about nor consent to being monitored; withholding, where participants are informed retroactively that they have been monitored and are given an opportunity to withhold consent; authorized deception, where participants are informed that the study will include a deceptive element, which will be revealed after the data collection; and full disclosure, where participants are informed and give consent to being monitored before data collection. ${ }^{62}$ Some authors have used concealed monitors ${ }^{16}$ or not informed study participants about the true purpose of the monitors, for example, saying that the monitors measure temperature but not that the purpose is to assess adherence. ${ }^{14}$ However, collecting data without the participants' knowledge, or without revealing its true purpose, could be ethically questionable, and it is not clear whether participants were debriefed afterward and given an opportunity to withdraw consent retroactively, which is recommended. ${ }^{61}$ The withholding approach is less questionable than stealth monitoring, but people may still feel that their integrity has been compromised and lose trust in researchers in the future. The authorized deception approach is less questionable, but it has not been used in studies on offloading devices. Naturally, the full disclosure approach is the least ethically questionable and could be valid if the monitors are used for a long time period during which they are not seen or felt, hopefully leading the participants to fall back into their everyday adherence pattern over time. Some temperature monitors can measure temperatures and store data for 100 days without any need to replace batteries or download data, which would have reminded the person about the monitoring. ${ }^{9}$ Unfortunately, many accelerometers do not yet have this capacity, and studies using accelerometers have typically collected data only for 7 days, ${ }^{12,14,17,45}$ although one study collected data for 35 days. ${ }^{16}$ Hopefully, future technological developments will expand the battery capacity and data storage of accelerometers, making it possible to collect data for longer time periods without interruptions. Thereby, both the methodological demands of unbiased data and the ethical requirements of informed consent could be fulfilled. In the meantime, the authorized deception approach seems to be a fruitful strategy for studies on adherence.

\section{Conceptual frameworks}

The conceptual framework chosen for the study is important for at least two reasons: first, it guides our choice of factors to study, that is, the factors that might affect adherence and second, it suggests causal mechanisms, that is, in what way the factors interact, which determines how to analyze the data. Quantitative studies on adherence to using offloading devices have so far not specified any conceptual framework, which may explain why different studies have investigated different factors that could affect adherence, ${ }^{30}$ and the rationale for choosing them is unclear. A review ${ }^{30}$ used the framework of the World Health Organization, ${ }^{63}$ categorizing factors into five dimensions: patient factors, therapy factors, condition factors, health system factors, and social and economic factors. The review concluded that most studies focus on patient, therapy, and condition factors, while factors related to the health system or patients' social and economic circumstances are often overlooked. ${ }^{30}$ This framework could be useful for future studies, but it specifies neither how the factors interact nor how time affects adherence; theoretical and qualitative studies suggest that adherence is a dynamic process in which beliefs, values, and behaviors interact and change over time..$^{24,33,64}$

Frameworks used in related fields could serve as a starting point and inspiration in future studies. For example, different models and concepts have been used to study which factors influence diabetic foot self-care practices and use of assistive technologies. The health belief model includes perceived seriousness of the health condition and perceived susceptibility to developing it, perceived benefits and barriers to engaging in healthy behavior, cues to action, and self-efficacy. ${ }^{65}$ Three out of four studies using this model found that at least one of the model's components was associated with adherence to diabetic foot self-care. ${ }^{66-69}$ The model could thus be useful for studying adherence to using offloading devices, and one study suggests that perceived benefits of therapeutic shoes are associated with a higher adherence. ${ }^{23}$ In the common-sense 
model of illness behavior, patients give meaning to their diagnosis and symptoms by constructing a mental model based on their lay knowledge, experiences, and significant others, guiding them in what actions to take. ${ }^{70}$ Three studies found that components of the model are associated with adherence to diabetic foot self-care. ${ }^{71-73}$ One instrument, the Patient Interpretation of Neuropathy questionnaire, was developed to address patients' common-sense understanding of diabetic neuropathy and foot ulcers, ${ }^{74}$ and one study using this questionnaire ${ }^{75}$ found an association between patients' misperceptions of their condition and potentially damaging self-care behaviors. The locus of control concept denotes to what extent people believe that outcomes of events are the results of their own actions or forces beyond their control. ${ }^{76}$ This concept has been associated with diabetic foot self-care, ${ }^{77}$ and it has been speculated that it can affect adherence to using offloading devices. ${ }^{33}$ A number of models have been developed to understand what factors influence the use of assistive technology. For example, one qualitative study $^{78}$ used a model by Lenker and Paquet ${ }^{79}$ to understand what factors influence the use of orthopedic shoes. However, some caution is warranted when applying models developed for assistive technology. Most assistive technologies aim to facilitate activities and participation in social life, which provides a positive incentive to use them. In contrast, offloading devices aim to prevent or treat diabetic foot complications but may at the same time hamper activities and participation (due to negative effects on gait and unaesthetic devices causing social stigma), ${ }^{24,64,80,81}$ providing a negative incentive to use them. Thus, the factors at play may differ between offloading devices and other assistive technologies.

\section{Discussion}

The aims of this methodological commentary were to discuss aspects of investigating adherence to using offloading devices among people with diabetes and provide recommendations for future studies. To date, studies have mainly used a cross-sectional, observational study design; defined adherence as device wearing time or number of steps taken with the device; measured adherence with questionnaires or monitors; and not used any explicit conceptual framework. In future, more longitudinal studies are recommended; there should be observational studies to identify patient groups prone to nonadherence and factors that influence adherence, and experimental studies should be used to evaluate interventions to improve adherence, focusing on these patient groups and factors. It is further recommended that adherence should be defined in terms of relative adherence to using offloading devices during all weight-bearing activities. Researchers should use objective methods (accelerometers and temperature monitors) to measure adherence whenever possible. Furthermore, a clearly defined conceptual framework should be adopted before the study is initiated, providing a rationale for what factors to study and how to analyze their interactions with each other and with adherence (Table 1).

In reality, these recommendations can sometimes conflict or not be practically feasible. For instance, although it would be ideal to use monitors to measure both adherence and nonadherence, it may not be feasible to put a monitor in every pair of shoes (therapeutic and conventional) that a person owns. Thus, a tradeoff may be needed, such that adherence is measured with a monitor in the offloading device, but self-report is used to distinguish different forms of nonadherence, for example, to separate wearing conventional shoes from standing and walking without shoes. Furthermore, to increase the generalizability of the results, researchers may want to include large groups of participants and then rely on questionnaires to assess adherence, although objective measurement methods are usually preferable. Thus, self-report

Table I Summary of dominating approaches in current research and recommendations for future studies

\begin{tabular}{|c|c|c|}
\hline Aspect & Dominating approaches in current research & Recommendations for future studies \\
\hline Study designs & Cross-sectional, observational & $\begin{array}{l}\text { Use longitudinal study designs with observational studies to identify } \\
\text { nonadherent patient groups and factors affecting adherence and } \\
\text { experimental studies to evaluate interventions to improve adherence }\end{array}$ \\
\hline $\begin{array}{l}\text { Definitions of } \\
\text { adherence }\end{array}$ & $\begin{array}{l}\text { Wearing time }{ }^{7-10,13,15,23,31,34,36,37} \text { or number of steps } \\
\text { taken with the device }{ }^{12,14,17,32,44,45}\end{array}$ & Define adherence as device use during all weight-bearing activities \\
\hline $\begin{array}{l}\text { Methods } \\
\text { to measure } \\
\text { adherence }\end{array}$ & $\begin{array}{l}\text { Interviews, }{ }^{10,11,13,31,36,37} \text { questionnaires, }{ }^{7,8,15,18,23,34,41} \\
\text { temperature monitors, }{ }^{9,12,14,43-45} \text { pedometers, }{ }^{12,14,17,32,44,45} \\
\text { and accelerometers }\end{array}$ & $\begin{array}{l}\text { Use objective methods (accelerometers and temperature monitors) } \\
\text { whenever possible. Validated questionnaires can be used for surveys }\end{array}$ \\
\hline $\begin{array}{l}\text { Conceptual } \\
\text { frameworks }\end{array}$ & $\begin{array}{l}\text { Frameworks not defined and focus on a narrow range } \\
\text { of factors (eg, patient-, therapy-, and condition-related } \\
\text { factors) }\end{array}$ & $\begin{array}{l}\text { Use clearly defined frameworks (eg, the health belief model or the } \\
\text { common-sense model of illness behavior) and include a wider range of } \\
\text { factors (eg, social and economic circumstances, health system-related } \\
\text { factors, locus of control, self-efficacy, and a time/process perspective) }\end{array}$ \\
\hline
\end{tabular}


is sometimes the most feasible alternative to measure adherence. Studies are needed to validate questionnaires that assess adherence to using offloading devices. When it comes to study design, experimental studies are more effective to counteract confounding than observational studies. However, several factors of interest, such as foot deformity and ulcer history, cannot be allocated to participants experimentally. Thus, observational studies are the only option for investigating such factors.

In future work with exploring and improving adherence to using offloading devices, researchers could benefit from methods and findings from other research fields facing similar challenges. For example, many parallels can be drawn between using offloading devices to prevent and heal diabetic foot ulcers and orthotic treatment of adolescent idiopathic scoliosis, as both interventions demand high- and long-term adherence; in both cases, the medical benefits of using the devices are uncertain and distant in time, in contrast with the disadvantages in terms of a negative impact on esthetics, clothing, function, activities, and social life, which are immediate. ${ }^{8,24,64,80,82-84}$ Furthermore, in both fields, electronic adherence monitoring has been suggested not only as a method to study adherence but as an intervention to improve adherence, although ethical concerns have been raised about this approach. ${ }^{48,85,86}$

Hopefully, this methodological commentary will contribute to discussions, reflections, and studies of high quality investigating factors that affect adherence to using offloading devices. In this way, patients in need of special support can be identified and effective interventions can be developed to increase adherence and thereby improve the outcomes for people with diabetic foot complications. Although this article focuses on adherence to using offloading devices among people with diabetes, the principles discussed may have a wider applicability. Thus, they can provide input to other research fields investigating adherence to using other forms of medical devices.

\section{Conclusion}

It is recommended that future studies use a longitudinal design with observational studies to identify patient groups prone to nonadherence and factors that influence adherence and experimental studies to evaluate interventions to improve adherence, addressing these patient groups and factors. Adherence should be defined in terms of relative adherence to using offloading devices during all weight-bearing activities, and objective measurement of adherence (using accelerometers and temperature monitors) should be used whenever possible. Clearly defined conceptual frameworks should guide the choice of factors to include in the study and the analysis of their interactions. Finally, a wider range of factors should be included in future studies.

\section{Acknowledgments}

The author thanks Lars-Olov Lundqvist, Associate Professor at Region Örebro County and Örebro University, for valuable comments on an earlier version of the manuscript. This study was supported by Region Örebro County, Sweden.

\section{Disclosure}

The author is a consultant for Novo Nordisk but does not consider this to be a conflict of interest in this work. The author reports no other conflicts of interest in this work.

\section{References}

1. Armstrong DG, Boulton AJM, Bus SA. Diabetic Foot Ulcers and Their Recurrence. N Engl J Med. 2017;376(24):2367-2375.

2. Armstrong DG, Wrobel J, Robbins JM. Guest Editorial: are diabetesrelated wounds and amputations worse than cancer? Int Wound J. 2007;4(4):286-287.

3. Wukich DK, Raspovic KM. Assessing Health-Related Quality of Life in Patients With Diabetic Foot Disease: Why Is It Important and How Can We Improve? The 2017 Roger E. Pecoraro Award Lecture. Diabetes Care. 2018;41(3):391-397.

4. Boulton AJ, Vileikyte L, Ragnarson-Tennvall G, Apelqvist J. The global burden of diabetic foot disease. Lancet. 2005;366(9498): 1719-1724.

5. Pecoraro RE, Reiber GE, Burgess EM. Pathways to diabetic limb amputation. Basis for prevention. Diabetes Care. 1990;13(5):513-521.

6. Prompers L, Huijberts M, Apelqvist J, et al. High prevalence of ischaemia, infection and serious comorbidity in patients with diabetic foot disease in Europe. Baseline results from the Eurodiale study. Diabetologia. 2007;50(1):18-25.

7. Paton JS, Stenhouse EA, Bruce G, Zahra D, Jones RB. A comparison of customised and prefabricated insoles to reduce risk factors for neuropathic diabetic foot ulceration: a participant-blinded randomised controlled trial. J Foot Ankle Res. 2012;5(1):31.

8. Macfarlane DJ, Jensen JL. Factors in diabetic footwear compliance. J Am Podiatr Med Assoc. 2003;93(6):485-491.

9. Ehrmann D, Spengler M, Jahn M, et al. Adherence Over Time: The Course of Adherence to Customized Diabetic Insoles as Objectively Assessed by a Temperature Sensor. J Diabetes Sci Technol. 2018;12(3):695-700.

10. Armstrong DG, Abu-Rumman PL, Nixon BP, Boulton AJ. Continuous activity monitoring in persons at high risk for diabetes-related lower-extremity amputation. J Am Podiatr Med Assoc. 2001;91(9): 451-455.

11. Knowles EA, Boulton AJ. Do people with diabetes wear their prescribed footwear? Diabet Med. 1996;13(12):1064-1068.

12. Bus SA, Waaijman R, Arts M, et al. Effect of custom-made footwear on foot ulcer recurrence in diabetes: a multicenter randomized controlled trial. Diabetes Care. 2013;36(12):4109-4116.

13. Chantelau E, Haage P. An audit of cushioned diabetic footwear: relation to patient compliance. Diabet Med. 1994;11(1):114-116.

14. Waaijman R, Keukenkamp R, de Haart M, Polomski WP, Nollet F, Bus SA. Adherence to wearing prescription custom-made footwear in patients with diabetes at high risk for plantar foot ulceration. Diabetes Care. 2013;36(6):1613-1618.

15. Mccabe CJ, Stevenson RC, Dolan AM. Evaluation of a diabetic foot screening and protection programme. Diabet Med. 1998;15(1) $80-84$. 
16. Crews RT, Shen BJ, Campbell L, et al. Role and Determinants of Adherence to Off-loading in Diabetic Foot Ulcer Healing: A Prospective Investigation. Diabetes Care. 2016;39(8):1371-1377.

17. Armstrong DG, Lavery LA, Kimbriel HR, Nixon BP, Boulton AJ. Activity patterns of patients with diabetic foot ulceration: patients with active ulceration may not adhere to a standard pressure off-loading regimen. Diabetes Care. 2003;26(9):2595-2597.

18. Ha van G, Siney H, Hartmann-Heurtier A, Jacqueminet S, Greau F, Grimaldi A. Nonremovable, windowed, fiberglass cast boot in the treatment of diabetic plantar ulcers: efficacy, safety, and compliance. Diabetes Care. 2003;26(10):2848-2852.

19. Bus SA, Armstrong DG, van Deursen RW, et al. IWGDF guidance on footwear and offloading interventions to prevent and heal foot ulcers in patients with diabetes. Diabetes Metab Res Rev. 2016;32 Suppl 1(Suppl 1):25-36.

20. Hingorani A, Lamuraglia GM, Henke P, et al. The management of diabetic foot: A clinical practice guideline by the Society for Vascular Surgery in collaboration with the American Podiatric Medical Association and the Society for Vascular Medicine. J Vasc Surg. 2016;63 (2 Suppl):3S-21S.

21. Cavanagh P. Footwear for people with diabetes: where are we now? Diabetic Foot J. 2007;10(4):193-194.

22. Breuer U. Diabetic patient's compliance with bespoke footwear after healing of neuropathic foot ulcers. Diabete Metab. 1994;20(4):415-419.

23. Arts ML, de Haart M, Bus SA, Bakker JP, Hacking HG, Nollet F. Perceived usability and use of custom-made footwear in diabetic patients at high risk for foot ulceration. J Rehabil Med. 2014;46(4):357-362.

24. Paton JS, Roberts A, Bruce GK, Marsden J. Patients' Experience of therapeutic footwear whilst living at risk of neuropathic diabetic foot ulceration: an interpretative phenomenological analysis (IPA). $J$ Foot Ankle Res. 2014;7(1):16.

25. Johnson M, Newton P, Goyder E. Patient and professional perspectives on prescribed therapeutic footwear for people with diabetes: a vignette study. Patient Educ Couns. 2006;64(1-3):167-172.

26. van Netten JJ, Jannink MJ, Hijmans JM, Geertzen JH, Postema K. Patients' expectations and actual use of custom-made orthopaedic shoes. Clin Rehabil. 2010;24(10):919-927.

27. van Netten JJ, Jannink MJ, Hijmans JM, Geertzen JH, Postema K. Long-term use of custom-made orthopedic shoes: 1.5-year follow-up study. J Rehabil Res Dev. 2010;47(7):643-649.

28. van Netten JJ, Jannink MJ, Hijmans JM, Geertzen JH, Postema K. Use and usability of custom-made orthopedic shoes. $J$ Rehabil Res Dev. 2010;47(1):73-81.

29. Williams AE, Nester CJ. Patient perceptions of stock footwear design features. Prosthet Orthot Int. 2006;30(1):61-71.

30. Jarl G, Lundqvist LO. Adherence to wearing therapeutic shoes among people with diabetes: a systematic review and reflections. Patient Prefer Adherence. 2016;10:1521-1528.

31. Kossioris A, Tentolouris N, Kyriazopoulou V, et al. Initial and continued adherence to wearing appropriate footwear in people with diabetic foot disease: results of a pilot study. Hellenic Journal of Nursing Science. 2017;10(4):21-28.

32. Keukenkamp R, Merkx MJ, Busch-Westbroek TE, Bus SA. An Explorative Study on the Efficacy and Feasibility of the Use of Motivational Interviewing to Improve Footwear Adherence in Persons with Diabetes at High Risk for Foot Ulceration. J Am Podiatr Med Assoc. 2018;108(2):90-99.

33. Jarl G, Lundqvist LO. Beyond dichotomous thinking: a process perspective on diabetic foot disease. Diabet Foot Ankle. 2017;8(1):1380477.

34. Churchman N. A retrospective audit of footwear use by high-risk individuals in North Derbyshire. Diabetic Foot J. 2008;11(1):10-18.

35. Rothman KJ. Epidemiology: an introduction. New York: Oxford University Press; 2002.

36. van Netten JJ, van Baal JG, Bril A, Wissink M, Bus SA. An exploratory study on differences in cumulative plantar tissue stress between healing and non-healing plantar neuropathic diabetic foot ulcers. Clin Biomech. 2018;53:86-92.
37. Bus SA, van Netten JJ, Kottink AI, et al. The efficacy of removable devices to offload and heal neuropathic plantar forefoot ulcers in people with diabetes: a single-blinded multicentre randomised controlled trial. Int Wound J. 2018;15(1):65-74.

38. Pollard JP, Le Quesne LP, Tappin JW. Forces under the foot. J Biomed Eng. 1983;5(1):37-40.

39. Sarnow MR, Veves A, Giurini JM, Rosenblum BI, Chrzan JS, Habershaw GM. In-shoe foot pressure measurements in diabetic patients with at-risk feet and in healthy subjects. Diabetes Care. 1994; 17(9):1002-1006.

40. Soames RW. Foot pressure patterns during gait. J Biomed Eng. 1985; $7(2): 120-126$

41. van de Weg B. Compliance with orthopaedic footwear in patients with diabetes. Diabetic Foot J. 2002;5(1):32-36.

42. Connor H, Mahdi OZ. Repetitive ulceration in neuropathic patients. Diabetes Metab Res Rev. 2004;20(Suppl 1):S23-S28.

43. Jarl G, Tranberg R. An innovative sealed shoe to off-load and heal diabetic forefoot ulcers - a feasibility study. Diabet Foot Ankle. 2017; 8(1): 1348178

44. Bus SA, Waaijman R, Nollet F. New monitoring technology to objectively assess adherence to prescribed footwear and assistive devices during ambulatory activity. Arch Phys Med Rehabil. 2012;93(11): 2075-2079.

45. Waaijman R, de Haart M, Arts ML, et al. Risk factors for plantar foot ulcer recurrence in neuropathic diabetic patients. Diabetes Care. 2014; 37(6):1697-1705.

46. Sangiorgio SN, Ho NC, Morgan RD, Ebramzadeh E, Zionts LE. The Objective Measurement of Brace-Use Adherence in the Treatment of Idiopathic Clubfoot. J Bone Joint Surg Am. 2016;98(19): 1598-1605.

47. Morton A, Riddle R, Buchanan R, Katz D, Birch J. Accuracy in the prediction and estimation of adherence to bracewear before and during treatment of adolescent idiopathic scoliosis. J Pediatr Orthop. 2008;28(3):336-341.

48. Donzelli S, Zaina F, Negrini S. In defense of adolescents: They really do use braces for the hours prescribed, if good help is provided. Results from a prospective everyday clinic cohort using thermobrace. Scoliosis. 2012;7(1):12

49. Najafi B, Crews RT, Wrobel JS. Importance of time spent standing for those at risk of diabetic foot ulceration. Diabetes Care. 2010;33(11): 2448-2450.

50. Proano E, Määttänen H, Perbeck L, Solders G, Turan I. The effect of weight-bearing pressure on the plantar circulation in diabetes mellitus. Diabet Med. 1992;9(8):722-729.

51. Cavanagh PR, Rodgers MM, Iiboshi A. Pressure distribution under symptom-free feet during barefoot standing. Foot Ankle. 1987;7(5): 262-278.

52. Rozema A, Ulbrecht JS, Pammer SE, Cavanagh PR. In-shoe plantar pressures during activities of daily living: implications for therapeutic footwear design. Foot Ankle Int. 1996;17(6):352-359.

53. Hills AP, Hennig EM, Mcdonald M, Bar-Or O. Plantar pressure differences between obese and non-obese adults: a biomechanical analysis. Int J Obes Relat Metab Disord. 2001;25(11):1674-1679.

54. Simoneau GG, Ulbrecht JS, Derr JA, Becker MB, Cavanagh PR. Postural instability in patients with diabetic sensory neuropathy. Diabetes Care. 1994;17(12):1411-1421.

55. Brown SJ, Handsaker JC, Bowling FL, Boulton AJ, Reeves ND. Diabetic peripheral neuropathy compromises balance during daily activities. Diabetes Care. 2015;38(6):1116-1122.

56. Najafi B, Grewal GS, Bharara M, Menzies R, Talal TK, Armstrong DG. Can't Stand the Pressure: The Association Between Unprotected Standing, Walking, and Wound Healing in People With Diabetes. J Diabetes Sci Technol. 2017;11(4):657-667.

57. Jao YL, Gardner SE, Carr LJ. Measuring Weight-Bearing Activities in Patients With Previous Diabetic Foot Ulcers. J Wound Ostomy Continence Nurs. 2017;44(1):34-40. 
58. Crews RT, Yalla SV, Dhatt N, Burdi D, Hwang S. Monitoring LocationSpecific Physical Activity via Integration of Accelerometry and Geotechnology Within Patients With or At Risk of Diabetic Foot Ulcers: A Technological Report. J Diabetes Sci Technol. 2017;11(5):899-903.

59. Grant PM, Ryan CG, Tigbe WW, Granat MH. The validation of a novel activity monitor in the measurement of posture and motion during everyday activities. Br J Sports Med. 2006;40(12):992-997.

60. Skotte J, Korshøj M, Kristiansen J, Hanisch C, Holtermann A. Detection of physical activity types using triaxial accelerometers. J Phys Act Health. 2014;11(1):76-84.

61. Levine RJ. Monitoring for adherence: ethical considerations. Am J Respir Crit Care Med. 1994;149(2 Pt 1):287-288.

62. Patel NU, Moore BA, Craver RF, Feldman SR. Ethical considerations in adherence research. Patient Prefer Adherence. 2016;10:2429-2435.

63. Sabaté E. Adherence to long-term therapies: Evidence for action. Geneva: World Health Organization; 2003.

64. Paton J, Roberts A, Glasser S, Collings R, Marsden J. "All I wanted was a pair of shoes": a qualitative case study. Diabetic Foot J. 2014; 17(3):100-106.

65. Rosenstock IM. Historical Origins of the Health Belief Model. Health Educ Monogr. 1974;2(4):328-335.

66. Chin YF, Huang TT, Hsu BR. Impact of action cues, self-efficacy and perceived barriers on daily foot exam practice in type 2 diabetes mellitus patients with peripheral neuropathy. $J$ Clin Nurs. 2013;22(1-2): 61-68.

67. Pham DT, Fortin F, Thibaudeau MF. The role of the Health Belief Model in amputees' self-evaluation of adherence to diabetes self-care behaviors. Diabetes Educ. 1996;22(2):126-132.

68. Robinson-Whelen S, Bodenheimer C. Health practices of veterans with unilateral lower-limb loss: Identifying correlates. $J$ Rehabil Res Dev. 2004;41(3B):453.

69. Sharifirad G, Hazavehi M, Baghianimoghadam M, Mohebi S. The effect of a Health Belief Model based education program for foot care in diabetic patients type II in Kermanshah, Iran (2005). Int J Endocrinol Metab. 2007;2:82-90.

70. Hagger MS, Orbell S. A Meta-Analytic Review of the CommonSense Model of Illness Representations. Psychol Health. 2003;18(2): 141-184.

71. Nie R, Han Y, Xu J, Huang Q, Mao J, Perception I. Illness perception, risk perception and health promotion self-care behaviors among Chinese patient with type 2 diabetes: A cross-sectional survey. Appl Nurs Res. 2018;39:89-96.

72. Vedhara K, Dawe K, Wetherell MA, et al. Illness beliefs predict self-care behaviours in patients with diabetic foot ulcers: a prospective study. Diabetes Res Clin Pract. 2014;106(1):67-72.
73. Vileikyte L. Psychosocial and behavioral aspects of diabetic foot lesions. Curr Diab Rep. 2008;8(2):119-125.

74. Vileikyte L, Gonzalez JS, Leventhal H, et al. Patient Interpretation of Neuropathy (PIN) questionnaire: an instrument for assessment of cognitive and emotional factors associated with foot self-care. Diabetes Care. 2006;29(12):2617-2624.

75. Perrin BM, Swerissen H, Payne CB, Skinner TC. Cognitive representations of peripheral neuropathy and self-reported foot-care behaviour of people at high risk of diabetes-related foot complications. Diabet Med. 2014;31(1):102-106.

76. Rotter JB. Generalized expectancies for internal versus external control of reinforcement. Psychol Monogr. 1966;80(1):1-28.

77. Abredari H, Bolourchifard F, Rassouli M, Nasiri N, Taher M, Abedi A. Health locus of control and self-care behaviors in diabetic foot patients. Med J Islam Repub Iran. 2015;29:283.

78. van Netten JJ, Dijkstra PU, Geertzen JH, Postema K. What influences a patient's decision to use custom-made orthopaedic shoes? $B M C$ Musculoskelet Disord. 2012;13:92.

79. Lenker JA, Paquet VL. A new conceptual model for assistive technology outcomes research and practice. Assist Technol. 2004;16(1):1-10.

80. van Deursen R. Footwear for the neuropathic patient: offloading and stability. Diabetes Metab Res Rev. 2008;24(Suppl 1):S96-S100.

81. Needleman RL. Successes and pitfalls in the healing of neuropathic forefoot ulcerations with the IPOS postoperative shoe. Foot Ankle Int. 1997;18(7):412-417.

82. Andersen MØ, Andersen GR, Thomsen K, Christensen SB. Early weaning might reduce the psychological strain of Boston bracing: a study of 136 patients with adolescent idiopathic scoliosis at 3.5 years after termination of brace treatment. J Pediatr Orthop B. 2002;11(2):96-99.

83. Matsunaga S, Sakou T, Nozoe S. Psychological effects of brace therapy on patients with idiopathic scoliosis. Journal of Orthopaedic Science. 1997;2(6):391-395.

84. Liskey-Fitzwater N, Moore CL, Gurel LM. Clothing Importance and Self-Perception of Female Adolescents with and without Scoliosis. Clothing and Textiles Research Journal. 1993;11(3):16-22.

85. Crews RT, Bowling FL, Boulton AJ. Controversies in off-loading: should big brother be watching? Curr Diab Rep. 2009;9(6):417-419.

86. Campbell JI, Eyal N, Musiimenta A, Haberer JE. Ethical Questions in Medical Electronic Adherence Monitoring. J Gen Intern Med. 2016;31(3):338-342.
Patient Preference and Adherence

\section{Publish your work in this journal}

Patient Preference and Adherence is an international, peer-reviewed, open access journal that focuses on the growing importance of patient preference and adherence throughout the therapeutic continuum. Patient satisfaction, acceptability, quality of life, compliance, persistence and their role in developing new therapeutic modalities and compounds to optimize

\section{Dovepress}

clinical outcomes for existing disease states are major areas of interest for the journal. This journal has been accepted for indexing on PubMed Central. The manuscript management system is completely online and includes a very quick and fair peer-review system, which is all easy to use. Visit http://www. dovepress.com/testimonials.php to read real quotes from published authors. 